\title{
Misconceptions About Evolution in Brazilian Freshmen Students
}

\author{
Rubens Pazza • Pierre R. Penteado • Karine F. Kavalco
}

Published online: 10 December 2009

(C) Springer Science+Business Media, LLC 2009

\begin{abstract}
Regarding such an important issue as our origin, as well as the origin of all biological diversity, it is surprising to realize that evolution still faces drawbacks in keeping its deserved notability as a unifying theory in biology. This does not happen because evolutionism lacks validity as a scientific theory, but rather because of several misconceptions regarding evolutionary biology that were and continue to be found in elementary and secondary education. Furthermore, mistaken evolutionary ideas also affect some philosophical and social issues. The aim of the present study was to evaluate knowledge about evolution among freshman students from distinct majoring areas at Universidade Estadual do Centro-Oeste do Paraná (UNICENTRO), Brazil. The research was carried out based on a ten-question questionnaire about evolution with distinct levels of difficulty, comprising the most observed misconceptions. In this study, 231 students attending classes in biological sciences (morning and evening schedule), exact sciences (agronomy, physics, chemistry, and math), and human sciences (history, geography, and pedagogy) were interviewed. The total average of right answers was $48.8 \%$, and the highest average per course obtained was $58.7 \%$ from the students attending biological sciences (evening schedule). Although evolutionary biology and ecology are supposed to represent teaching guide issues according to the recommendations of the National Curricular Parameters
\end{abstract}

Electronic supplementary material The online version of this article (doi:10.1007/s12052-009-0187-3) contains supplementary material, which is available to authorized users.

R. Pazza $(\bowtie) \cdot$ P. R. Penteado · K. F. Kavalco

Laboratório de Genética Ecológica e Evolutiva,

Universidade Federal de Viçosa (UFV), Campus Rio Paranaíba,

Rodovia BR 354, km 310, Campus Universitário, P.O. Box 22,

Rio Paranaíba, MG 38810-000, Brazil

e-mail: rpazza@ufv.br for the Secondary School, the data obtained suggest that the evidence for evolution, the role of natural selection and random events, as well as the sources of variation, must be better focused at schools.

Keywords Darwin · Evolutionary biology .

Teaching evolution $\cdot$ Misconceptions

\section{Introduction}

Biological evolution or changes in inherited traits is a very popular and intuitive idea. Nevertheless, despite being emphatically corroborated again and again with new scientific publications, there remains widespread lack of understanding about the theory. It is certainly possible that people with at least a little education have already heard of Darwin, who outlined the theory of evolution. On the other hand, evolutionary theory is likely one of the most unknown theories, quite susceptible to misunderstandings and, thereby, to the diffusion of mistaken concepts.

Tidon and Lewontin (2004) realized that one of the greatest shortcomings in teaching evolution is unfortunately related to the background of teachers. Although a group of teachers insisted when interviewed that Darwinian and Lamarckian theories about changes in living beings are easy to teach those same teachers showed a clear agreement with the Lamarckism hypothesis when answering specific questions (Tidon and Lewontin 2004). Furthermore, religious issues can also contribute to difficulties in comprehending evolution. According to Rutledge and Mitchell (2002), either the acceptance or rejection of evolutionary theory as a valid scientific explanation may influence students' comprehension of evolutionary thought. In addition to the problems with teaching evolution at schools, 
there is also the lack of qualification or even the negligence of the media, which almost always presents contents with either mistaken or fuzzy concepts (Pazza and Kavalco 2007).

In the present study, we ascertained whether comprehension about basic evolutionary concepts is related to the majoring field of freshman students and evaluated the level of misconceptions incorporated by such students.

\section{Material and Methods}

In the present study, 231 freshman students from Universidade Estadual do Centro-Oeste do Paraná (Brazil) were interviewed. These students were attending classes both in biological sciences (morning and evening schedule), exact sciences (agronomy, physics, chemistry, and math), and human sciences (history, geography, and pedagogy) courses. The research was carried out using a ten-question questionnaire about evolution, comprising the chief issues of evolutionary theory in distinct levels of difficulty (the questionnaire is in Electronic supplementary material). A quantitative method was chosen, thus comprising a significant sample of evaluated questionnaires.

The results from the research were tabulated and analyzed, obtaining both the descriptive statistics and the demonstrative graphs. The data were submitted to analysis of variance (ANOVA) and Tukey's comparative average test. Additionally, unweighted pair group method with arithmetic mean (UPGMA) clustering and principal component analyses were performed in order to test the majoring fields grouping based on the Manhattan similarity index. The statistical analyses were performed using the software PAST v1.67b (Hammer et al. 2001).

\section{Results and Discussion}

The total average of correct answers obtained by the students was $48.8 \%$, in which the highest average (58.7\%) belonged to the biological sciences (evening schedule) course (Fig. 1a). Questions 1 and 10 are highlighted for presenting the highest level of right answers, while question 4 showed the lowest average (Fig. 1b).

The ANOVA showed that the differences in the score obtained by the students from distinct courses were significant ( $p=0.01719$ ), and the variance in the average could be observed by Tukey's comparative test (Table 1). In the analysis focusing on the majoring area, a remarkable difference in the average between biological sciences courses and the others was shown. Nonetheless, the analysis revealed a great similarity between exact and human sciences courses (Table 2). The differences in the average scores among the
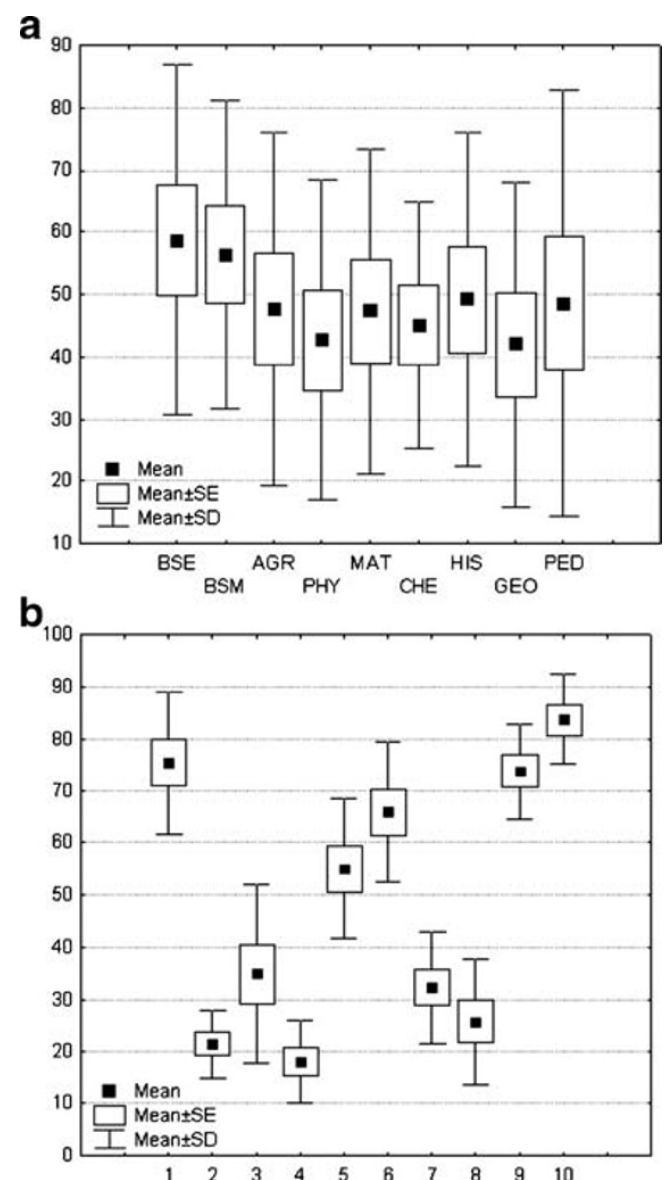

Fig. 1 Means, SD, and standard error found in the research with freshman studies by a course and $\mathbf{b}$ question

major fields of knowledge are clearly shown in the overall average graphs per question (Fig. 2a) within biological sciences (Fig. 2b), exact sciences (Fig. 2c), and human sciences (Fig. 2d) courses. The principal component analysis clustered the courses belonging to the same field of knowledge (Fig. 3), in which the first component was responsible for $43.4 \%$ of the total variance. The Manhattan similarity index with 1,000 repetitions used in the UPGMA dendrogram suggests a stronger relationship among the biological sciences courses when compared to the others (Fig. 4). Coupled with the principal component analysis, such a result reinforces the course clustering according to its field of knowledge.

The results obtained seem to be in agreement with the hypothesis that the acceptance of evolutionary theories influences its further understanding (Rutledge and Mitchell 2002). Students attending biological sciences courses are likely to accept evolutionary theories, thus being able to gain better comprehension of them. On the other hand, aptitude for this field may influence students' focus on the subject of biology. Although a student's religious option is an important factor to take into 
Table 1 Tukey's average comparison by course $-Q \backslash p$

BSE Biological Sciences (evening), $B S M$ Biological Sciences (morning), AGR Agronomy, PHY Physics, MAT Math, CHE Chemistry, HIS History, GEO Geography, PED Pedagogy

\begin{tabular}{llllllllll}
\hline & BSE & BSM & AGR & PHY & MAT & CHE & HIS & GEO & PED \\
\hline BSE & & 0.9991 & 0.1715 & 0.643 & 0.2012 & 0.09222 & 0.4572 & 0.01131 & 0.6926 \\
BSM & 0.9458 & & 0.5663 & 0.959 & 0.616 & 0.3948 & 0.8764 & 0.09163 & 0.9721 \\
AGR & 3.728 & 2.782 & & 0.9974 & 1 & 1 & 0.9999 & 0.9919 & 0.9952 \\
PHY & 2.627 & 1.681 & 1.101 & & 0.9987 & 0.9833 & 1 & 0.7477 & 1 \\
MAT & 3.628 & 2.682 & 0.1001 & 1.001 & & 1 & 1 & 0.9868 & 0.9974 \\
CHE & 4.08 & 3.134 & 0.3519 & 1.453 & 0.452 & & 0.9978 & 0.9991 & 0.9743 \\
HIS & 3.003 & 2.057 & 0.7256 & 0.3753 & 0.6256 & 1.078 & & 0.8852 & 1 \\
GEO & 5.029 & 4.084 & 1.301 & 2.402 & 1.401 & 0.9492 & 2.027 & & 0.701 \\
PED & 2.524 & 1.578 & 1.205 & 0.1035 & 1.104 & 1.556 & 0.4789 & 2.506 & \\
\hline
\end{tabular}

consideration, this aspect has not been examined in our study. Furthermore, student difficulty in memorizing scientific content is neither exclusive to Brazilian schools nor to evolutionary theory in general (Alters and Nelson 2002). Thus, special attention should be given to these matters in future.

In the following sections, issues are discussed according to the questions answered by the students.

\section{Question 1 and Question 9-Darwin and Lamarck}

Questions 1 and 9 are related to the historical perspective of evolutionary ideas, taking into account the thoughts of the most renowned thinkers (Darwin and Lamarck). Lamarck was an important name in the rise of evolutionary biology. He supposed that lineages of species persisted indefinitely, changing from one form into another, without branch or extinction. Such changes would be due to an "internal force." Lamarck is also identified with a belief in the inheritance of acquired characters, although it is not really a Lamarckian idea (Ridley 2004). According to Darwin, because of the struggle for existence, forms that are better adapted to survive will leave more offspring and automatically increase in frequency from one generation to the next (Ridley 2004).

Question 1 was ranked in second place regarding the right answers, reaching an average of over $75 \%$. This suggests that the differential aspect of Darwin's theory (the struggle for survival where individuals with advantageous traits would reproduce more successfully) was clear to students from secondary school. Nevertheless, about $27 \%$

Table 2 Tukey's average comparison by area- $Q \backslash p$

\begin{tabular}{llll}
\hline & Biological & Exact & Human \\
\hline Biological & & 0.00074 & 0.001148 \\
Exact & 5.181 & & 0.9925 \\
Human & 5.015 & 0.1656 & \\
\hline
\end{tabular}

of students from the chemistry course reported that Darwin's main idea about the way living beings change was based on the use and disuse theory. The chemistry course showed the lowest grade in this question (only $50 \%$ of right answers). Remarkably, the students from exact sciences got about $70 \%$ right answers, while the students from biological sciences got $90 \%$ correct answers in this question.

These results agree with those found in question 9 (particularly about Lamarck) where the average of right answers was close to $74 \%$ with a low standard deviation $(\mathrm{SD}=9.2)$. According to Tidon and Lewontin (2004), teachers usually assure that theories about modifications in living organisms (Darwin and Lamarck) are easy to teach. Apparently, the difference between those theories is accepted and comprehended by students, mainly by those that have chosen a biological field as a profession. A high index of right answers referring to the question about Darwin was obtained by the students of biological sciences; however, the question related to Lamarck did not show the same index, which was close to $78 \%$. It is possible that some of the students might have been distracted while choosing as a correct alternative that the long neck of giraffes has evolved through the higher fitness of individuals displaying such trait, without noticing that, actually, this question dealt with Lamarck's explanation and not Darwin's. After all, this concept is widely used in textbooks. On the other hand, although the teachers claim that it is easy to teach the subject of evolution, their answers to some questions show a clear agreement with the Lamarckian hypothesis (Tidon and Lewontin 2004), suggesting that the students' misinterpretation may have a deeper implication.

Question 8-Homologies and Analogies

The homologies are one of the main evidences of biological evolution. Different structures are homologous when they have a common ancestral origin. Widespread examples are related to human arms, whale flippers, and bat wings. Although with distinct functions, they have a common 

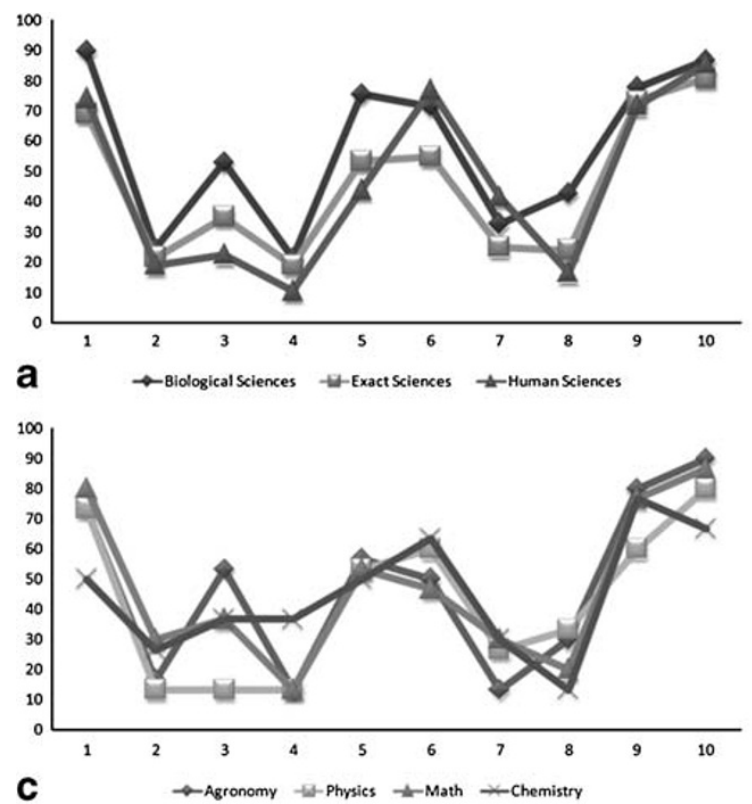

Fig. 2 Overall average graphs per question a among all knowledge areas and within the b Biological Science courses, c Exact Science courses, and d Human Science courses. BS Biological Sciences, ES Exact Sciences, HS Human Sciences, BSE Biological Sciences

embryologic origin. Homologies differ from analogies, which are not evidences of evolution. Analogies are similar in function but do not necessarily show a common origin; that is, they do not rely on a common ancestor. Such is the case of whale and fish flippers, which have the same function but distinct origins. How can we explain that one of the main evidences of evolution among the students interviewed attained an average of a mere $25 \%$ of right answers? Interestingly, other research with secondary
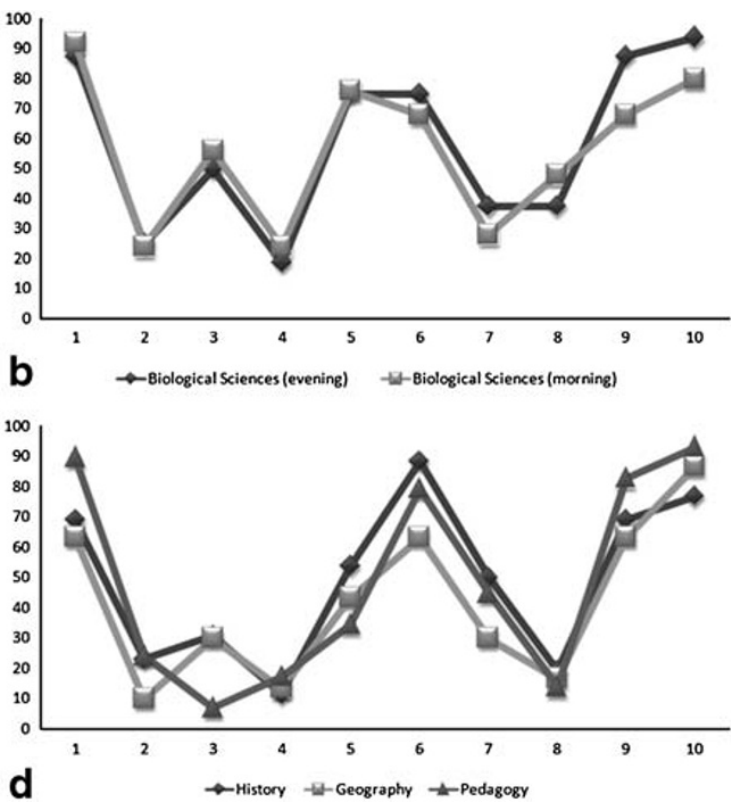

(evening), BSM Biological Sciences (morning), AGR Agronomy, PHY Physics, MAT Math, CHE Chemistry, HIS History, GEO Geography, PED Pedagogy

students shows that the idea that similarities among organisms may be due to a kind of kinship among them could be an unconscious bias of anthropomorphic thinking (Kampourakis and Zogza 2008).

Are textbooks deficient regarding this content or is the problem with teachers who are not able to convey the evidence due to their own and/or their students' sociocultural concepts? Since the comprehension of evolution depends on its acceptance (Rutledge and Mitchell 2002),
Fig. 3 Course clustering according to its field of knowledge by principal component analysis

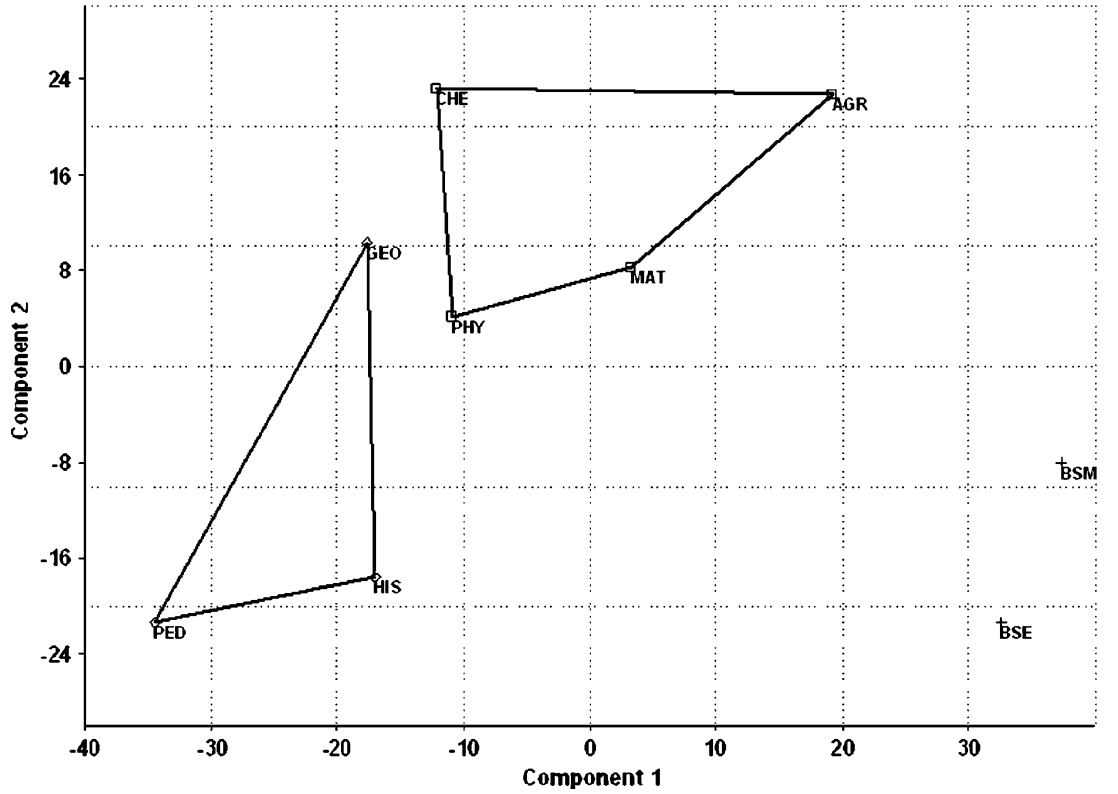


Fig. 4 UPGMA dendrogram based on Mahalanobis similarity index with 1,000 repetitions bootstrap

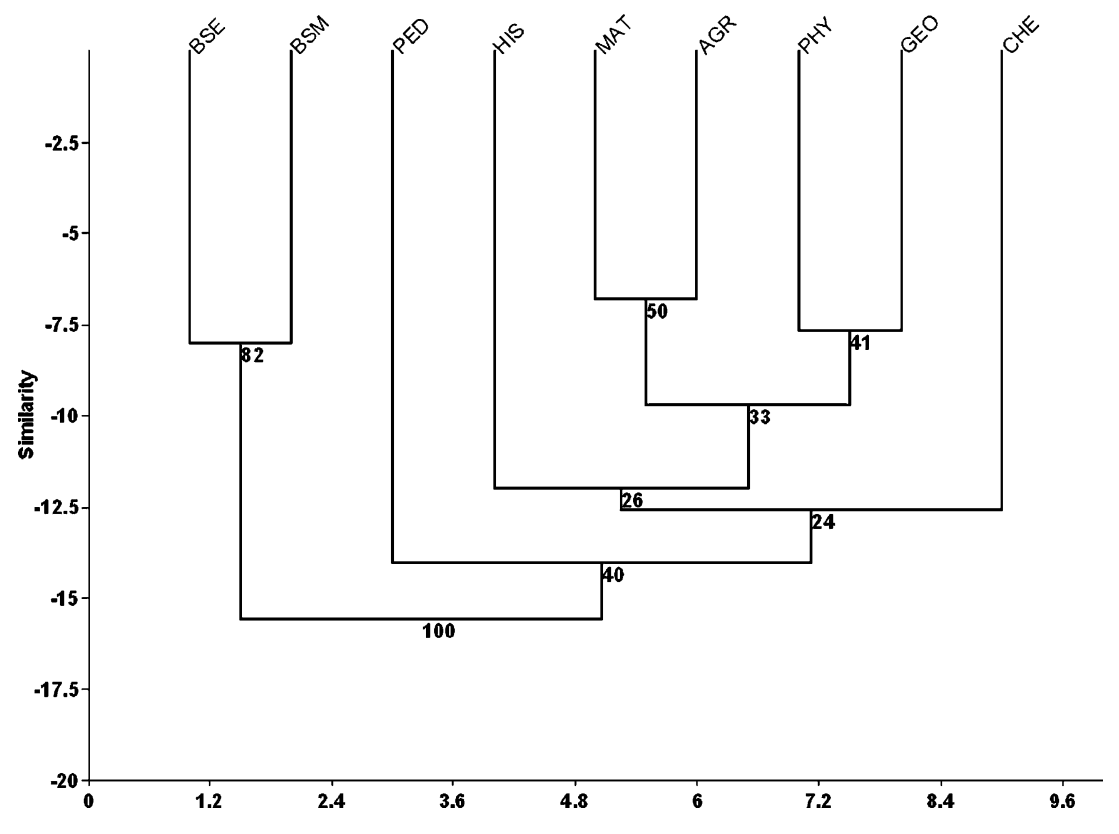

it is not surprising that issues related to the concept formation of teachers themselves arise because of their personal convictions (Tidon and Lewontin 2004; Bloom and Wiseberg 2007; Meglhioratti et al. 2005).

It is important to point out that the students from the biological sciences got about $42 \%$ of the answers right, which is considerably higher than the average.

Questions 3, 4, and 10-Variation and Natural Selection

Natural selection is one of the main theories outlined by Darwin to explain both the history of life and of biodiversity. Nevertheless, natural selection will only take place if variation is produced in association with a differential fitness status among individuals bearing certain variations. Those variations that restrain or cause any damage to the individuals are likely to be eliminated, while advantageous variations tend both to be kept and to increase in frequency within the population.

The aim of question 10 was to assess the widespread misconception that considers the majority of mutations either deleterious or harmful. In the face of the redundant genetic code, the abundance of no coding genetic material, the need of mutation in gametic cells (in order to be transmitted to next generations), just to name a few considerations, the majority of mutations actually tend to be neutral. Although selecting only "true" or "false" for the frequent statement that the majority of mutations are harmful, the students achieved an average of more than $80 \%$ right answers. Therefore, it was expected that the students knew that mutations are sources of variation. But do they know that such mutations are not the only source of variation? Question 4 plainly showed that they do not even know that recombination plays a key role as a source of variation; they also failed to distinguish the origin of variation from natural selection itself. In several cases, including students from biological sciences, natural selection was emphasized as a source of variation. That question hit the lowest index of right answers with an average of $17.95 \%$.

The misinterpretation regarding the role of natural selection is even more evident in question 3-"When a given variation provides both a higher survival rate and the possibility to be transmitted to other generations, its frequency increases in the population through a process called..." This question showed the highest SD (16.99) with an average of $34.75 \%$ right answers, although the students from biological sciences once more had a better performance $(53 \%)$. In particular, the use and disuse theory was pointed out as the correct alternative by a higher percentage of students from the pedagogy course when compared to the students that chose the right answer.

Comprehension of the concept of natural selection and its role in evolution seems to be complicated and bound to be misunderstood (Tidon and Lewontin 2004; Bishop and Anderson 1990). Historically, natural selection was initially rejected, although the economic climate at Darwin's time was favorable for its acceptance (Mayr 2004). The fact that the natural explanation about changes in living beings relies on natural selection and ignores finalist causes might be considered the crucial point for its rejection and even its misinterpretation. Moreover, such fact emphasizes an exception regarding the benefits of the externalist view of science (Jenkins 1996) widespread throughout the current educational scenario. Perhaps, before searching for the historical characteristics that have led a scientist to outline 
a given idea, it would be interesting to understand the whole idea at first, thereby avoiding the spreading of misconceptions.

\section{Questions 5, 6, and 7-Human Evolution}

The questions related to human evolution showed rather divergent results. The students in the human sciences courses performed better when asked about hominid species and chronology (questions 6 and 7) and had higher averages compared to students in the other courses. Nevertheless, the biological sciences courses surpassed the others when the questions touched on evolution itself (question 5). A possible explanation for this finding is the fact that the students from biological sciences tend to perceive the human being as a part of the ecosystem; i.e., they consider humans as another piece of the evolutionary process and not isolated beings with a unique evolutionary history in relation to the other species. This misconception can be seen through the wrongly chosen alternatives in which a remarkable number of students from both exact and human sciences pointed out that the human being is the most evolved organism, showing a plain misunderstanding of the difference between evolution and progress. Meglhioratti et al. (2005) impute this type of mistake to language misuse since the interviewed teachers seemed to use the words "evolution" and "adapt" in a daily connotation, although in biology such words do not have the sense of progress.

\section{Question 2-The Random Effect}

Random effects play a key role in evolution. Mutation, representing the main source of variation, happens at random. Likewise, the frequency of genes considered neutral (without adaptive value) varies randomly. Nevertheless, random effects are not responsible for natural selection.

The average of the most unlikely alternative chosen"random effect is natural selection"-is, again, more important than the average of right answers itself (21.6\%). This finding corroborates the misinterpretation about natural selection as well as its role in evolution. Selection reflects a variation conferring either an advantageous or a deleterious fitness on individuals. Random selection is a "raffle," no matter the characteristic or its adaptive value. We can, at random, take a ball out of a box containing twenty identically sized balls and we will not be able to know which one was removed. Nonetheless, if there is a variation in their size, it is feasible to open a hole on the box where only balls with a given size will pass through it. In that case, we are selecting the balls that pass through the hole; that is, it does not happen at random.

\section{Final Considerations}

The fact that species do change in the long term has faced no objections by either the scientific community or the population in general. Nevertheless, the idea that natural selection is one of the engines of evolution took some time to gain acceptance (for a brief review, see Meglhioratti et al. 2005). The data obtained in this research show that, although most students accept inheritance with changes, they do not understand how evolution occurs. In particular, they do not know about the role of random effects, variation, and natural selection in the evolutionary process. Additionally, some other misconceptions were previously mentioned in this study, such as the confusion evolution with progress (Alters and Nelson 2002; Bishop and Anderson 1990; Bizzo 2007).

Meglhioratti et al. (2005) found similar shortcomings in a qualitative analysis performed with biology teachers. The authors pointed out the lack of well-defined scientific concepts, the misuse of language, and the teachers' belief and religion as possible explanations. In this present study, we were also able to observe that the students' choice of a given majoring field is correlated to their knowledge of biological evolution.

An increasing concern among the academic communities in the world over the last decades has been the teaching and learning of biological evolution, especially in the USA (Scott and Branch 2003). Alters and Nelson (2002) point out some significant events related to this issue, such as the summons to the Evolution Education Research Conference, the organization of an educational committee in the Society for the Study of Evolution, among others. However, such actions are restricted to the North American scientific academy in an attempt to solve a set of problems raised by the teaching of evolution in that country. In Brazil, a Society for the Study of Evolution has neither been created yet (during the time this article was submitted), nor has a committee (or in any other scientific society) engaged in the study of issues related to the teaching of evolution. Furthermore, biological evolution is not a subject area supported by activist organizations. Although weak, creationist movements are gaining more and more traction in Brazilian universities, suggesting that a scientific society for the study of evolution should be created in order to avoid further mistakes.

Although evolutionary biology and ecology are supposed to represent teaching guide issues according to the recommendations of the National Curricular Parameter for the Secondary School, the difficulty in teaching such science is higher than expected (Tidon and Lewontin 2004; Meglhioratti et al. 2005). Jensen and Finley (1996) have found that using a historically rich curriculum in conjunction with a paired problem-solving strategy will 
improve students' use of Darwinian conceptions and decrease their use of alternative concepts, in a precourse and postcourse investigation. Nevertheless, it is known that teachers' backgrounds and the quality of teaching are closely related; hence, it is necessary that biology teachers have an accurate knowledge about both evolutionary theory and its essential role in biology. Such background is not always achieved in classes about evolution at universities. Teachers should make use of scientific articles as well as scientific divulgation books and texts in order to improve their formation as professionals of education.

Rutledge and Mitchell (2002) also suggest that teachers must be aware of how scientific knowledge is produced. In their studies, these authors have also observed, using concept maps, that the level of teachers' knowledge about evolutionary biology was closely related to their own acceptance of evolutionary theory. Thus students' difficulty in learning is not only related to comprehension of the evolutionary processes, processes but also to reluctance in accepting the theory as a valid scientific theoretical explanation for natural phenomena related to the origin of all biodiversity. Very often, antievolutionary adepts refer to the word "theory" in a pejorative sense, conferring on it nonexistent hierarchical degrees in the philosophy of science about the definition of a theory or a scientific fact. In doing so, their purpose is to lessen the effects of biological evolution comprehension. Saying that "evolution is just a theory" sounds reasonable to untutored ears, thus attention should not be given to it. Considering this, science classes, particularly those in secondary education must start with an explanation of the scientific method, hypothesis formulation, and feasibility tests of a scientific theory.

In addition, it is important that teachers demonstrate to their students that evolution, besides being a theory used to explain biodiversity, can also be seen in agriculture, health, and society. Evolutionary study is also underlies the current huge concern about the preservation of biodiversity. Avise (2003) hopes that, in the near future, in humanity's search for sustainable development, evolutionary biology, genetics, and ecology will lead the way to a new environmental ethics.
Acknowledgements The authors thank the coordination of the courses of the Universidade Estadual do Centro-Oeste do Parana that have taken part in the research for the opportunity granted.

\section{References}

Alters BJ, Nelson CE. Perspective: teaching evolution in higher education. Evolution. 2002;56:1891-901.

Avise JC. The best and the worst of times for evolutionary biology. Bioscience. 2003;53(3):247-55.

Bishop BA, Anderson CW. Students conceptions of natural selection and its role in evolution. J Res Sci Teach. 1990;27(5):415-27.

Bizzo NMV. From down house landlord to Brazilian high school students: what has happened to evolutionary knowledge on the way? J Res Sci Teach. 2007;31(5):537-56.

Bloom P, Wiseberg DS. Childhood origins of adult resistance to science. Science. 2007;316:996-7.

Hammer O, Harper DAT, Ryan PD. PAST: palaeontological statistics software package for education and data analysis. Palaeontol Electronica. 2001;4:1-9.

Jenkins EW. The 'nature of science' as a curriculum component. J Curric Stud. 1996;28(2):137-50.

Jensen MS, Finley FN. Changes in students' understanding of evolution resulting from different curricular and instructional strategies. J Res Sci Teach. 1996;33(8):879-900.

Kampourakis K, Zogza V. Students' intuitive explanations of the causes of homologies and adaptations. Sci Educ. 2008;17:27-47.

Mayr E. What makes biology unique? Considerations on the autonomy of a scientific discipline. Cambridge: Cambridge University Press; 2004.

Meglhioratti FA, Bortolozzi J, Caldeira AMA. História da biologia: Aproximações entre as possíveis categorias históricas e as concepções sobre ciência e evolução apresentadas pelos professores de biologia. In: Caldeira A, Caluzi J, editors. Filosofia e história da ciência - contribuições para o ensino de ciência. Ribeirão Preto: Kayrós Editora; 2005. p. 11-28.

Pazza R, Kavalco KF (2007) Imprecisão e licença científica, o retorno. Observ Imp 12:461. Available at http://observatorio.ultimosegundo. ig.com.br/artigos.asp?cod=461 OFC001

Ridley M. Evolution. 3rd ed. Malden: Blackwell; 2004. p. 751.

Rutledge ML, Mitchell MA. High school biology teachers' knowledge structure, acceptance and teaching of evolution. Am Biol Teach. 2002;64(1):21-8.

Scott EC, Branch G. Evolution: what's wrong with 'teaching the controversy'. Trends Ecol Evol. 2003;18(10):499-502.

Tidon R, Lewontin RC. Teaching evolutionary biology. Genet Mol Biol. 2004;27(1):124-31. 